\title{
Twig-like middle cerebral artery: a rare condition not to be confused with Moyamoya disease
}

Twig-like middle cerebral artery: uma condição rara que não pode ser confundida com doença de Moyamoya Igor PAGIOLA',2, Leonardo ABAURRE', Pedro PIANCA', Derval PIMENTEL '1, Leandro BARBOSA

Twig-like MCA is a rare anomaly with prevalence of $0.1-1 \%$ in literature ${ }^{1}$, possibly explained by failure fusion of primitive $\mathrm{MCA}^{2}$. Pathogenesis is not fully understood. Hemorrhage $(50 \%)^{3}$, cerebral ischemia (Figure 1), aneurysm or incidental fidings the clinical presentation. It's important to know this entity not to misdiagnose as Moyamoya or steno-occlusive disease ${ }^{4}$.
Features of Tw-MCA are reported and presented in our case (Figures 2, 3 and 4) 2 .

Moyamoya has different characteristics from Tw-MCA: progressive bilateral terminal carotid occlusion with MCA, ACA involvement and extensive lenticulostriate collaterals.
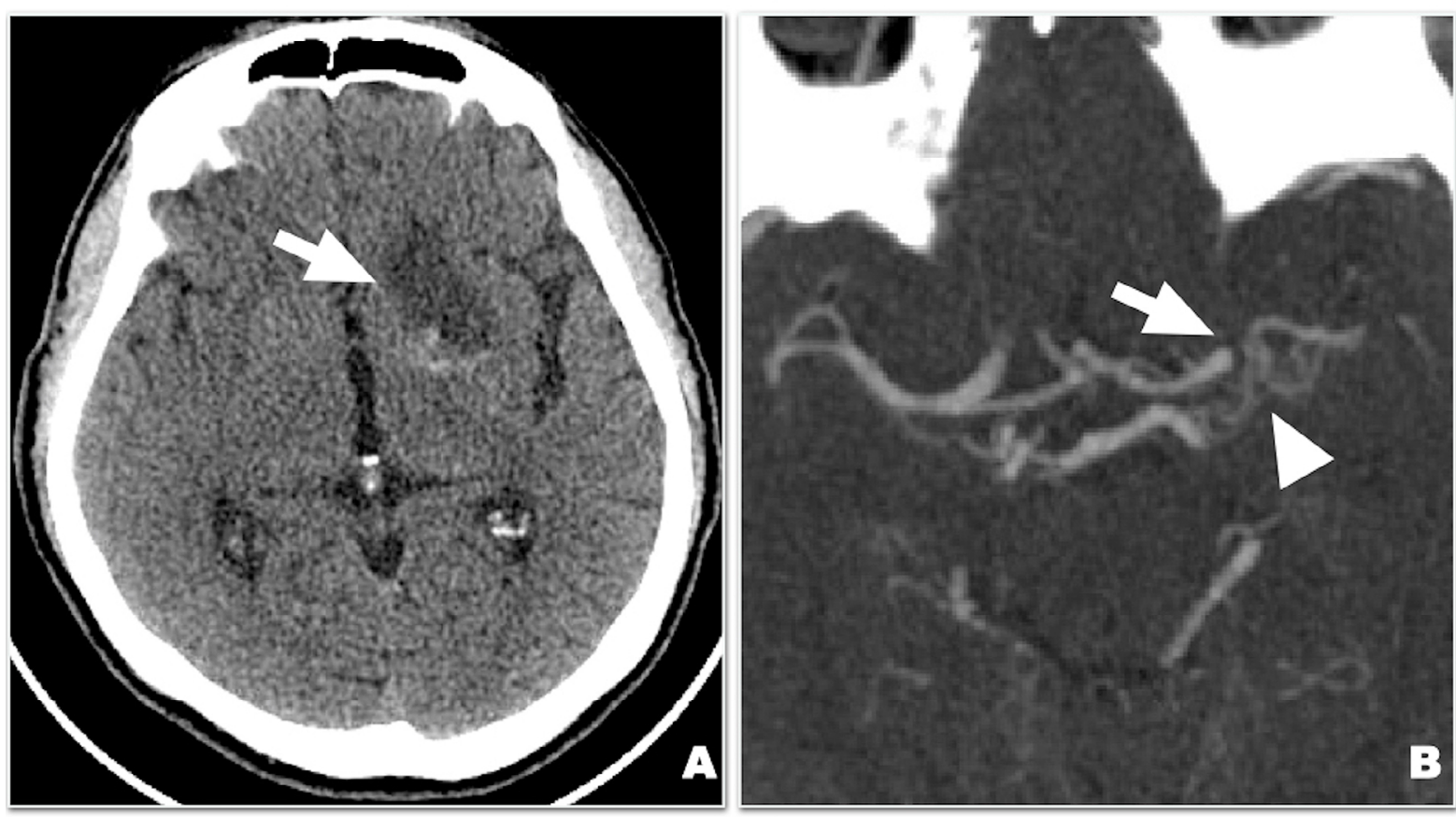

Figure 1. A) Axial non contrast Brain CT with hypodensity on the striatocapsular area (arrow); B) Axial intracranial CT angiography (CTA) image with MCA occlusion (arrow) and anastomotic vessels (arrowhead) to the distal part of the MCA trunk.

${ }^{1}$ Hospital Estadual Central, Departamento de Neurorradiologia Intervencionista, Vitória ES, Brazil.

${ }^{2}$ Escola Superior de Ciências da Santa Casa de Misericórdia de Vitória, Hospital da Santa Casa de Vitória, Departamento de Neurologia, Vitória ES, Brazil. IP (D) https://orcid.org/0000-0001-9052-7946; LA (1D https://orcid.org/0000-0001-7053-9384; PP (D) https://orcid.org/0000-0001-7651-3169;

DP (ID https://orcid.org/0000-0001-9619-2294; LB (10) https://orcid.org/0000-0002-9762-1078

Correspondence: Igor Pagiola; Email: igorpagiola@hotmail.com.

Conflict of interest: There is no conflict of interest to declare.

Authors' contributions: All authors contributed equally to this work.

Received on April 13, 2021; Received in its final form on April 30, 2021; Accepted on May 08, 2021. 

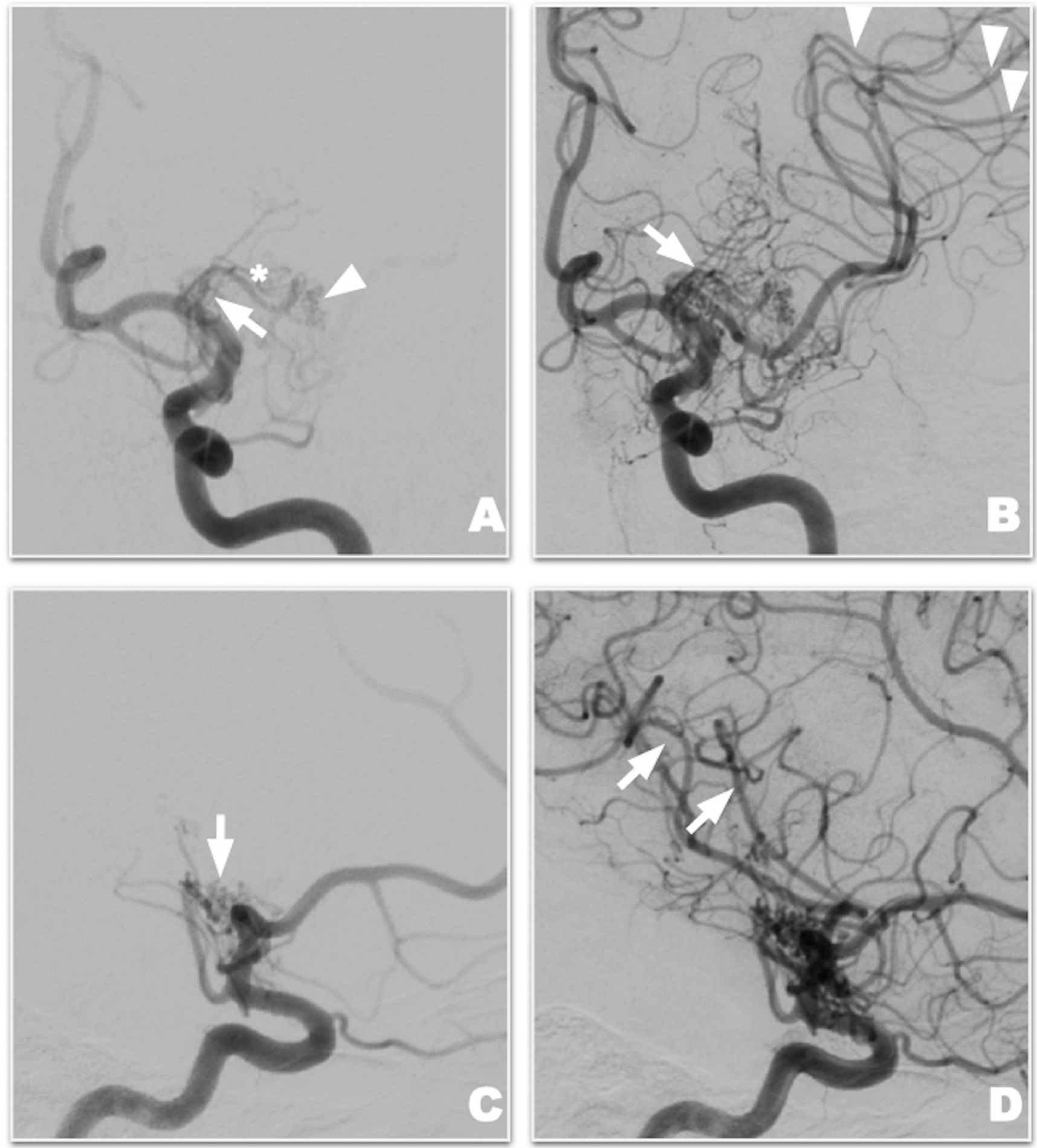

Figure 2. Four Features of Twig-Like MCA:A) DSA frontal view of early arterial phase of the left ICA with 1) unilateral proximal M1 occlusion (arrow) and 2) plexiform arterial network instead of MCA trunk (arrowhead); anomalous artery from left A1 segment (asterisk); B) Late arterial phase DSA of the left ICA with 3) Perforators from the plexiform network (arrow) and 4) Cortical branches beyond occluded MCA trunk with anterograde flow with normal configuration (arrowhead); C) DSA lateral view of early arterial phase of the left ICA with the plexiform arterial network (arrow); D) DSA lateral view of early arterial phase of the left ICA with cortical branches beyond occluded MCA trunk with anterograde flow with normal configuration (arrow). 

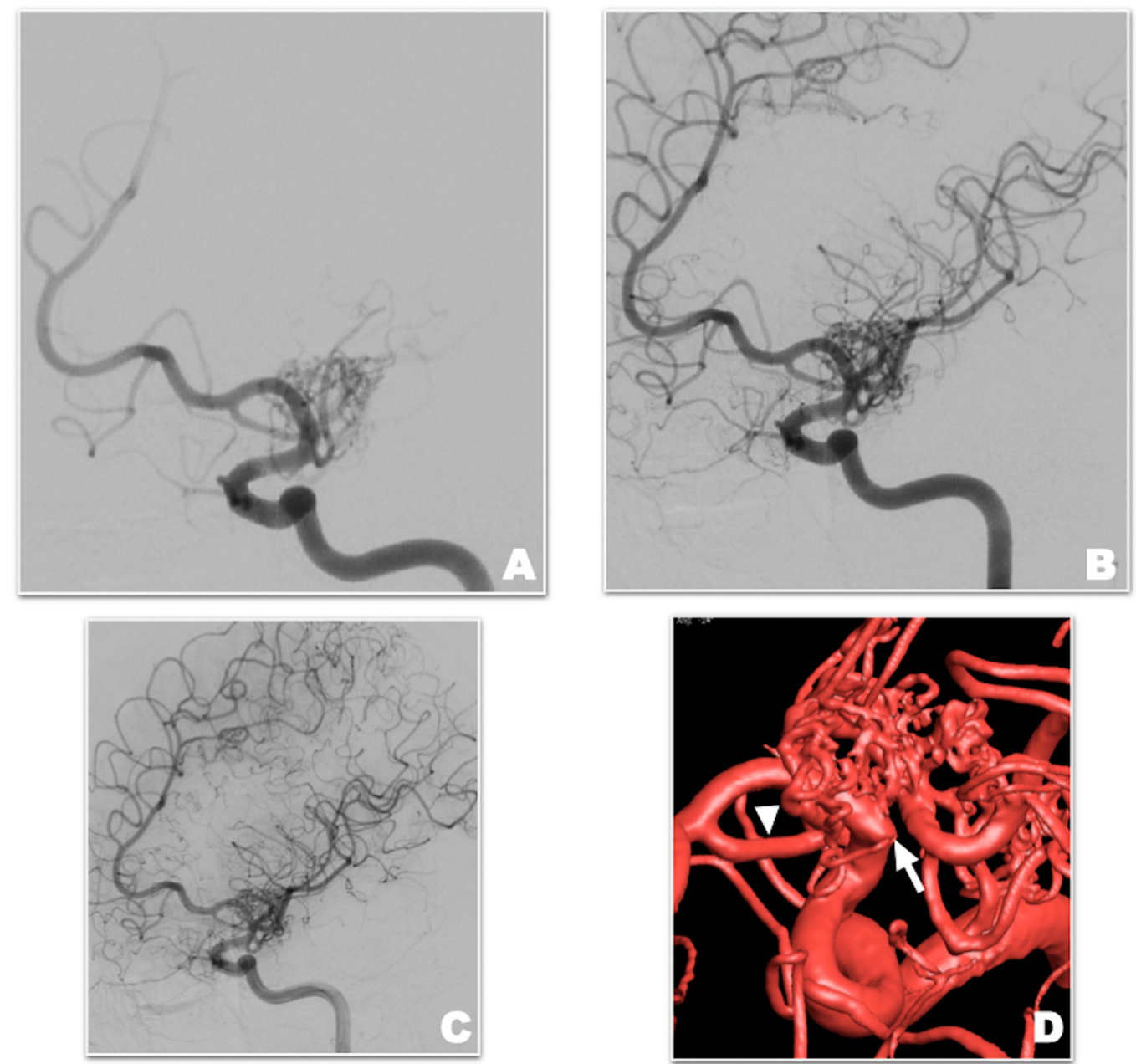

Figure 3. A) DSA oblique view of early arterial phase of the left ICA; B) DSA oblique view of late arterial phase of the left ICA; C) DSA oblique view of arterial phase of the left ICA with leptomeningeal collaterals from the distal left anterior cerebral artery and distal branches of MCA; D) Diagnostic DSA 3D reconstruction of the left ICA with the MCA occlusion (white arrow); and an anomalous artery from left A1 segment of the ACA (arrowhead). Also, the plexiform arterial network instead of MCA trunk is demonstrated with the normal distal MCA trunk.
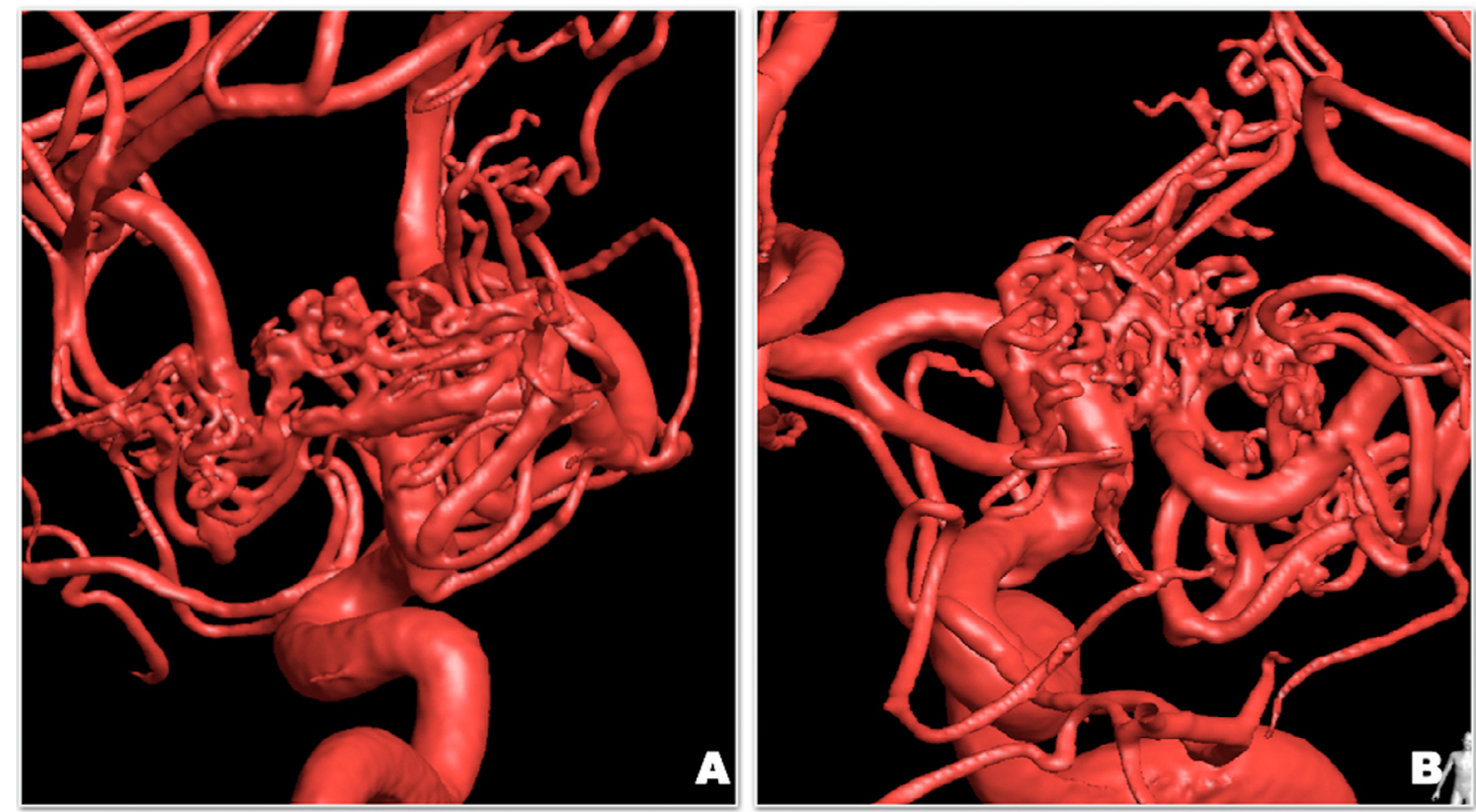

Figure 4. A) Diagnostic DSA 3D reconstruction of the left ICA with the plexiform arterial network; B) Diagnostic DSA 3D reconstruction of the left ICA with the plexiform arterial network and the normal distal MCA trunk. 


\section{REFERENCES}

1. Goto Y, Oka H, Hiraizumi S, Okamoto T, Nishii S, Yamamoto H, et al. Aplastic or Twig-Like middle cerebral artery presenting with intracerebral hemorrhage during pregnancy: report of two cases. World Neurosurg X. 2019 Feb 5;2:100018. https://doi.org/10.1016/j. wnsx.2019.100018

2. Uchiyama N. Anomalies of the middle cerebral artery. Neurol Med Chir (Tokyo). 2017 Jun 15;57(6):261-6. https://doi.org/10.2176/nmc. ra.2017-0043
3. Viso R, Lylyk I, Albiña P, Lundquist J, Scrivano E, Lylyk P. Hemorrhagic events associated with unfused or twig-like configuration of the middle cerebral artery: a rare vascular anomaly with clinical relevance. Interv Neuroradiol. 2021 Apr 1;27(2):285-90. https://doi. org/10.1177/1591019920970430

4. Onoue K, Nguyen TN, Mian A, Dasenbrock H, Bedi H, Abdalkader M. Twig-like middle cerebral arteries: Clinical and radiological findings. Clin Imaging. 2021 May;73:31-7. https://doi.org/10.1016/j. clinimag.2020.11.049 